\title{
NHS launches Race and Health Observatory after BMJs call to end inequalities
}

\section{Zosia Kmietowicz}

The BMJ

A new NHS centre to investigate the effects of race and ethnicity on people's health has got the go ahead after a special issue of The BMJ in February focused on the continuing problem of racism in medicine.

Earlier this year Mala Rao and Victor Adebowale, who guest edited the special issue (bmj.com/racism-in-medicine), called for an independent "observatory" to "inform action towards the overarching NHS race equality goals."

Simon Stevens, NHS England's chief executive, has now approved the NHS Race and Health Observatory after agreeing to establish the centre "in principle" at The BMJ's event to launch the special issue, at which he joined a panel discussion on the challenges faced by doctors and patients from ethnic minority groups.

Rao and Adebowale said they were delighted with the news. Rao noted that the funding of an observatory was "a significant step further forward in terms of achieving an end to race inequalities in health and health care."

The announcement comes amid rising concern about the particular impact of covid-19 on people from ethnic minority groups. A review into the effects of covid-19 on these groups was due at the end of May, but Public Health England was unable to say when it would be published.

NHS England said that the observatory would involve experts from the UK and overseas and would offer analysis and policy recommendations to improve health outcomes for NHS patients, communities, and staff. A meeting hosted by The BMJ on 12 June will aim to decide the way forward.

Stevens said, "Ethnicity and race have been shown systematically to influence our health, independent of factors such as age, sex, and socioeconomic status. While the NHS has made some strides in workforce race equality, and although tackling wider inequalities cannot fall to the NHS alone, the health service has to both listen and lead as part of the solution. This new centre will therefore bring together expertise to offer practical, useful suggestions for change."

Adebowale, chair of the NHS Confederation, which will host the observatory, said, "The impact of covid-19 on black and minority ethnic communities and healthcare staff has shone the brightest of lights on racial inequalities and their root causes. The NHS Race and Health Observatory will be critical in identifying and helping to transform the disproportionate effects that race is having on patients, communities, and NHS staff. This has the potential to be a step change towards a new era of greater equality."

Chaand Nagpaul, BMA council chair, commented, "An NHS Race and Health Observatory is long overdue: we have known for a long time that there are racial inequalities in health and the care people receive.

"The covid-19 pandemic has heightened awareness of this, with higher mortality and hospitalisation rates of our BAME healthcare workers and communities. It has also highlighted the need for a more systematic approach to collecting data on race and health, better engagement with BAME healthcare workers, and better assimilation of academic research, enabling the NHS and public health system to learn and respond more effectively to trends.

"An observatory offers this opportunity, helping us to understand the factors affecting the health of our black, Asian, and other minority ethnic populations and take appropriate actions to enable equality. We look forward to engaging with it."

Adebowale V, Rao M. Racism in medicine: why equality matters to everyone. $B M J$ 2020;368:m530. 10.1136/bmj.m530 32051166

Published by the BMJ Publishing Group Limited. For permission to use (where not already granted under a licence) please go to http://group.bmj.com/group/rights-licensing/ permissions 